Tropical Journal of Pharmaceutical Research November 2021; 20 (11): 2287-2292

ISSN: $1596-5996$ (print); 1596-9827 (electronic) (C) Pharmacotherapy Group, Faculty of Pharmacy, University of Benin, Benin City, 300001 Nigeria

\title{
Pregabalin alleviates postherpetic neuralgia by downregulating spinal TRPV1 channel protein
}

\author{
Zhenping Xiao ${ }^{1}$, Mengjun Liao ${ }^{2}$, Yunwu He${ }^{1}$, Yonglin $\mathrm{Li}^{1}$, Wuzhou Yang ${ }^{1}$, Liping \\ Jiang ${ }^{1}$, Cong Zou ${ }^{1 *}$ \\ ${ }^{1}$ Department of Pain Rehabilitation, Second Affiliated Hospital, ${ }^{2}$ Department of Anesthesiology, South China Affiliated Hospital, \\ University of South China, Hengyang 421001, Hunan Province, China
}

*For correspondence: Email: wxrj4i@163.com

Sent for review: 1 August 2021

Revised accepted: 22 October 2021

\begin{abstract}
Purpose: To determine the mechanism involved in pregabalin-induced alleviation of postherpetic neuralgia in a rat model.

Methods: Ninety-sixty healthy Sprague-Dawley (SD) rats were assigned to sham, model and pregabalin groups (32 rats per group). A model of postherpetic neuralgia (PN) was established. The expressions of IL-1 $\beta$ and TNF- $\alpha$ in spinal cord tissue were determined 7 days after administration of treatments. The proportions of fluorescence areas in astrocytes in the dorsal horn, prefrontal lobe and hippocampus, and level of spinal cord TRPV1 channel protein in each group were evaluated.

Results: Relative to model rats, IL-1 $\beta$ and TNF- $\alpha$ in spinal cord of pregabalin rats were significantly reduced $(p<0.05)$. The areas of fluorescence in astrocytes in dorsal horn of spinal cord, prefrontal lobe and hippocampus of model group were significantly increased, relative to sham, but were decreased in rats in pregabalin group $(p<0.05)$.

Conclusion: Pregabalin significantly alleviates postherpetic neuralgia via mechanisms which may be related to the inflammatory response of spinal dorsal horn and downregulation of TRPV1 channel protein expression. This finding may be useful in developing new drugs for alleviating postherpetic neuralgia.
\end{abstract}

Keywords: Pregabalin, Spinal TRPV1 channel protein, Herpes zoster, Neuralgia, Mechanism

\begin{abstract}
This is an Open Access article that uses a funding model which does not charge readers or their institutions for access and distributed under the terms of the Creative Commons Attribution License (http://creativecommons.org/licenses/by/4.0) and the Budapest Open Access Initiative (http://www.budapestopenaccessinitiative.org/read), which permit unrestricted use, distribution, and reproduction in any medium, provided the original work is properly credited.
\end{abstract}

Tropical Journal of Pharmaceutical Research is indexed by Science Citation Index (SciSearch), Scopus, International Pharmaceutical Abstract, Chemical Abstracts, Embase, Index Copernicus, EBSCO, African Index Medicus, JournalSeek, Journal Citation Reports/Science Edition, Directory of Open Access Journals (DOAJ), African Journal Online, Bioline International, Open-J-Gate and Pharmacy Abstracts

\section{INTRODUCTION}

Herpes zoster is an acute skin disease caused by herpes zoster virus. In the elderly, herpes zoster neuralgia is the most common complication of herpes zoster, and it manifests as a burning, tearing or knife-cut pain which results in difficulty in eating, decline in quality of life decline, and anxiety or depression [1]. The pathogenesis of postherpetic neuralgia is still not clearly understood. However, based on the pathological changes it induces in the nervous system, the disease is thought to be a type of neuropathic pain. Therefore, it is of great significance to study the pathogenesis of the disease and provide relevant scientific evidence for its therapy. Studies have found that the outcome of treatment for herpes zoster is closely 
related to the time of onset: the shorter the duration of the disease, the earlier the treatment time and the better the treatment effect [2].

At present, the clinical treatment of postherpetic neuralgia involves the use of nucleoside analogs, antidepressants and local anesthetics. Although these strategies have resulted in some measure of efficacy, they are associated with toxic side effects [3]. Pregabalin, a new anticonvulsant and a first-line drug approved by the US Food and Drug Administration for the treatment of neuropathic pain, relieves pain, regulates sleep function, combats anxiety, and inhibits neuronal excitability [4]. However, the mechanism involved in its effect on postherpetic neuralgia is still unclear. In this study, the effect of pregabalin on a rat model of postherpetic neuralgia, and the mechanism involved, were investigated.

\section{EXPERIMENTAL}

\section{Animals}

Ninety-six healthy male SD rats aged 6 weeks, with mean body weight of $228 \pm 20 \mathrm{~g}$, were obtained from Chongqing Best Biological Technology Co. Ltd [production license SCXK (Chongqing) 2018-0004, SYXK (Chongqing) 2018-0004]. The rats were maintained at a laboratory at temperature of $23 \pm 1^{\circ} \mathrm{C}$ and humidity of $50 \pm 10 \%$ under 12 -h light/12-h dark photoperiod, and were allowed ad libitum access to feed and water (adaptive feeding) for 7 days prior to commencement of the study. This study received approval from the Animal Ethics Committee of University of South China (approval no. 20200182), and was conducted according to "Principles of Laboratory Animal Care" [5].

\section{Equipment and reagents}

The major instruments and reagents used, and their suppliers were: constant temperature water bath (Tianjin Hengao Science and Technology Development Co. Ltd, model: HWT-20B); ultralow temperature refrigerator (Hangzhou Aipu Instrument Equipment Co. Ltd, model: AP-6060LA); electronic balance (Jinan Noble Laboratory Equipment Co. Ltd, model: EX225D); phosphate buffer (Beijing Wanjia Shouhua Biological Technology Co. Ltd); enzyme linked immunoassay kit (Mercak Biotech Ltd); phosphate buffer (Shanghai Yuanye Biotechnology Co. Ltd), and pregabalin (Chongqing Saiwei Pharmaceutical Co. Ltd, production batch number: 20190073, specification: $75 \mathrm{mg} \times 10$ tablets).

\section{Study design}

The rats were assigned to sham, $\mathrm{PN}$ model and pregabalin groups ( $n=32$ each). A rat model of postherpetic neuralgia was established viz: resinous toxin $(40 \mu \mathrm{g} / \mathrm{mL})$ solution was prepared by dissolving $1 \mathrm{mg}$ of the toxin in a mixture of 2.5 $\mathrm{mL}$ of $10 \%$ Tween $80,2.5 \mathrm{~mL}$ of $10 \%$ ethanol and $20 \mathrm{~mL}$ of $80 \%$ normal saline. Model and pregabalin rats received intraperitoneal injection of resinous toxin solution at a dose of $200 \mu \mathrm{g} / \mathrm{kg}$, while rats in the sham group were given injection saline in place of toxin. The pregabalin group was given pregabalin $(0.03 \mathrm{~g} / \mathrm{kg})$ for one week following establishment of the model. The injection was given once daily for 7 days.

\section{Parameters evaluated}

Thermal and mechanical pain thresholds (TMPTs) of each group were measured using thermal pain measuring instrument and electronic pain measuring instrument, respectively. In the determination of mechanical pain threshold, the rats were put on an elevated metal cage in a quiet environment with constant temperature and humidity. The plantar surface of each rats was stimulated with filaments from a vertical angle. The stimulus was gradually increased until the rat appeared to lift and lick their feet.

The environment for measuring thermal pain threshold was the same as that for mechanical pain threshold. When the rats were quiet, they were placed on the stimulation hot plate. When the rats showed positive reactions such as foot lifting and licking, the times were recorded and the critical value was set at $30 \mathrm{sec}$. A total of 4 measurements were made, and the mean value of multiple measurements was recorded. The interval between tests was $15 \mathrm{~min}$. Changes in mechanical pain threshold and thermal pain threshold were measured before establishment of the PN model, 1 week after PN model established, and 1 week after treatment.

One week after treatment, 8 rats were selected from each group. The spinal dorsal horn tissue levels of IL-1 $\beta$ and TNF- $\alpha$ of rats were determined. The tissue was homogenized and centrifuged, and an appropriate amount of chloroform was added to the supernatant. The supernatant was centrifuged, and total RNA was precipitated by addition of appropriate amounts of isopropanol and $75 \%$ ethanol. The RNA was reverse-transcribed to cDNA in reaction system at $42{ }^{\circ} \mathrm{C}$. One week after administration, spinal dorsal horn and brain tissues were taken from 12 rats in each group. The fluorescence areas of 
astrocytes in spinal dorsal horn, prefrontal lobe and hippocampus were determined using immunofluorescence method. The frozen tissues were processed into $30-\mu \mathrm{m}$ thick sections, washed with phosphate buffer solution, sealed with BSA solution, and subjected to overnight incubation at $4^{\circ} \mathrm{C}$ with $1^{\circ}$ immunoglobulins, prior to incubation with secondary immunoglobulin at $37{ }^{\circ} \mathrm{C}$ for $60 \mathrm{~min}$, natural drying, sealing and examination under a fluorescence microscope.

The expression levels of transient receptor potential vanilloid type1 (TRPV1) channel protein were determined with immunohistochemistry and western blot assays. Immunohistochemistry, the spinal cord tissues were processed into paraffin sections which were dehydrated and dewaxed. Antigen recovery was done by incubation of the paraffin sections in sodium citrate antigenrepairing solution. Then, the sections were sealed with goat serum, prior to incubation overnight at $4{ }^{\circ} \mathrm{C}$ with primary antibody for TRPV1, rinsing with phosphate buffer, and incubation with secondary antibody at $37^{\circ} \mathrm{C}$ for $30 \mathrm{~min}$. Thereafter, the sections were stained with $D A B$ and counterstained with hematoxylin, followed by dehydration, clearing and sealing. Finally, the stained sections were examined under a microscope. For Western blotting, total protein was extracted from spinal cord tissue by homogenization in ice-cold lysis buffer, and the homogenate was incubated for $30 \mathrm{~min}$ and centrifuged, and lysate protein content was measured with BCA procedure. Then, the proteins were resolved with SDS-polyacrylamide gel electrophoresis and transferred to PVDF membranes. The membranes were subjected to overnight incubation at $4^{\circ} \mathrm{C}$ with $1^{\circ}$ antibody for TRPV1, prior to treatment with secondary antibody linked to HRP at room temperature for 1 h. The bands were visualized with SignalFire ${ }^{\mathrm{TM}}$ Plus ECL system, while Image J software (vers. 2) was employed for quantification.

\section{Statistics}

Data are presented as mean \pm standard deviation (SD). Comparison amongst multiple groups was done with univariate mean, while two-group comparison was done with independent sample $t$-test. Statistical evaluations were done with SPSS 24.0 software. Statistical significance was assumed at $p<0.05$.

\section{RESULTS}

\section{Mechanical pain thresholds and thermal pain thresholds (TMPTs)}

Before modeling, there were no significant differences between TMPTs amongst the three groups $(p>0.05)$. However, relative to sham group, mechanical pain threshold in model rats was markedly reduced 1 week after establishing the PN model and 1 week after treatment, while the thermal pain threshold was significantly increased $(p<0.05)$. Compared with model group, mechanical pain threshold was significantly increased, while thermal pain threshold was significantly decreased 1 week after treatment $(p<0.05)$. These results are presented in Table 1.

\section{Levels of TNF- $\alpha$ and IL-1 $\beta$ in rat spinal cord tissue}

The expression levels of these cytokines in spinal cord of model rats were significantly increased, relative to the corresponding levels in the sham operation group. However, their expression levels in spinal cord on pregabalintreated rats were significantly decreased ( $p<$ 0.05). These results are shown in Table 2.

\section{Fluorescent areas of astrocytes in rat spinal dorsal horn, prefrontal lobe and hippocampus}

Compared with sham group, the percentage of fluorescent areas in astrocytes in dorsal horn of spinal cord, prefrontal lobe and hippocampus of model group were significantly increased, but were markedly decreased in rats in pregabalin group $(p<0.05)$. These results are presented in Figure 1 and Table 3.

Table 1: Comparison of TMPTs amongst the groups

\begin{tabular}{|c|c|c|c|c|c|}
\hline Group & Sham & Model & Pregabalin & $F$ & $P$-value \\
\hline \multicolumn{6}{|c|}{ Mechanical pain thresholds (g) } \\
\hline Before PN model & $46.58 \pm 2.33$ & $46.79 \pm 1.52$ & $45.87 \pm 2.33$ & 2.91 & 0.060 \\
\hline 1 week after $\mathrm{PN}$ model & $46.28 \pm 2.83$ & $8.79 \pm 1.82^{\mathrm{a}}$ & $9.51 \pm 2.07^{a}$ & 2827.65 & $<0.001$ \\
\hline 1 week after treatment & $45.17 \pm 2.24$ & $9.31 \pm 1.79^{a}$ & $24.26 \pm 2.37^{\mathrm{ab}}$ & 2250.71 & $<0.001$ \\
\hline \multicolumn{6}{|c|}{ Thermal pain threshold (s) } \\
\hline After PN model & $7.28 \pm 1.57$ & $7.24 \pm 0.83$ & $7.86 \pm 1.32$ & 2.36 & 0.100 \\
\hline 1 week after PN model & $7.38 \pm 1.68$ & $24.46 \pm 2.34^{a}$ & $24.36 \pm 1.82^{a}$ & 799.36 & $<0.001$ \\
\hline 1 week after treatment & $7.46 \pm 0.81$ & $25.74 \pm 2.13^{a}$ & $12.40 \pm 1.25^{\mathrm{ab}}$ & 1270.71 & $<0.001$ \\
\hline
\end{tabular}

Data are mean \pm SD. ${ }^{\text {a, }}{ }^{b} P<0.05$, vs sham $\left({ }^{a}\right)$; vs model $\left({ }^{b}\right)$ 
Table 2: Levels of IL-1 $\beta$ and TNF- $\alpha$ in the pulp tissue of rats (mean $\pm \mathrm{SD}$ )

\begin{tabular}{lll}
\hline Group & IL-1 $\beta$ & TNF- $\alpha$ \\
\hline Sham & $0.98 \pm 0.04$ & $1.00 \pm 0.01$ \\
Model & $1.54 \pm 0.22^{\mathrm{a}}$ & $1.66 \pm 0.35^{\mathrm{a}}$ \\
Pregabalin & $1.21 \pm 0.26^{\mathrm{ab}}$ & $1.27 \pm 0.21^{\mathrm{ab}}$ \\
$F$ & 16.17 & 15.85 \\
$P$-value & $<0.001$ & $<0.001$ \\
\hline $\mathrm{a}, \mathrm{b} P<0.05$, vs sham $\left({ }^{\mathrm{a}}\right) ;$ vs model $\left({ }^{\mathrm{b}}\right)$ &
\end{tabular}
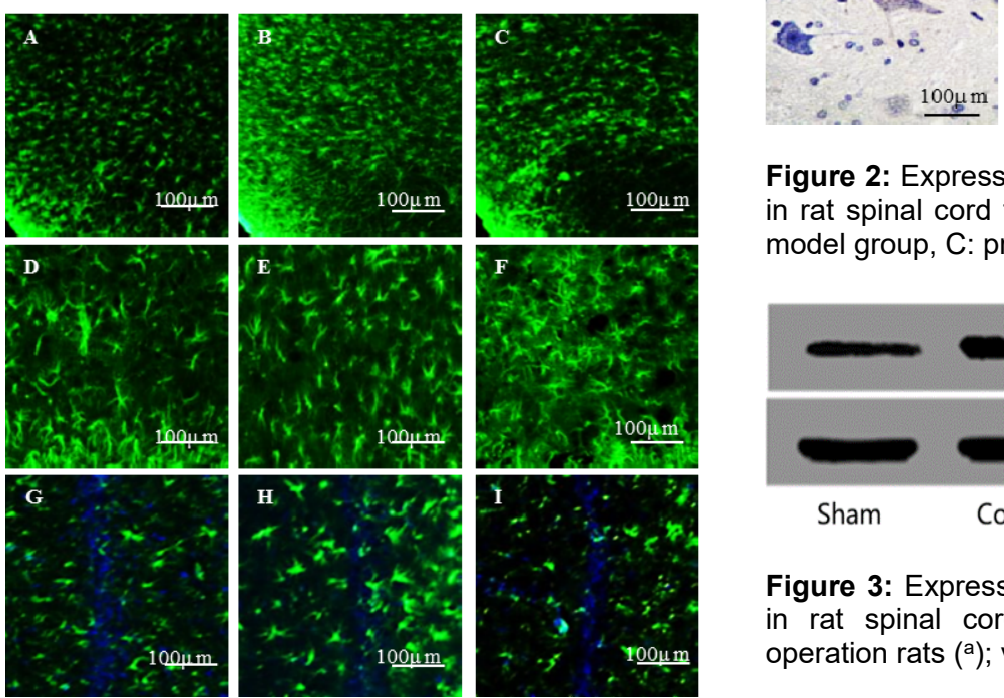

Figure 1: Relative fluorescence areas of astrocytes in spinal dorsal horn, prefrontal lobe and hippocampus of rats in each group. A-C: Spinal dorsal horn tissues of sham group (A), PN model rats $(B)$ and pregabalintreated rats $(C)$. D -F: Prefrontal tissues of sham group (D), model group $(E)$, and pregabalin group $(F)$. G-I: Hippocampal CA1 tissues of sham group (G), model group $(\mathrm{H})$ and pregabalin group $(\mathrm{I})$

Table 3: Fluorescent areas in astrocytes in spinal dorsal horn, prefrontal lobe and hippocampus of rats $(\%, n=12)$

\begin{tabular}{lccc}
\hline Group & $\begin{array}{c}\text { Spinal } \\
\text { cord }\end{array}$ & $\begin{array}{c}\text { Prefrontal } \\
\text { lobe }\end{array}$ & $\begin{array}{c}\text { CA1 of } \\
\text { hippocampus }\end{array}$ \\
\hline $\begin{array}{l}\text { Sham } \\
\text { operation }\end{array}$ & $\begin{array}{c}9.68 \pm 0 . \\
92\end{array}$ & $12.24 \pm 1.32$ & $6.55 \pm 0.81$ \\
group & & & \\
Model & $16.85 \pm$ & $17.45 \pm 0.57$ & $12.41 \pm 1.82^{\mathrm{a}}$ \\
group & $0.79^{\mathrm{a}}$ & $\mathrm{a}$ & \\
Pregabalin & $11.43 \pm$ & $\begin{array}{c}14.65 \pm 0.79 \\
\text { ab }\end{array}$ & $8.87 \pm 0.57^{\mathrm{ab}}$ \\
group & $1.32^{\mathrm{ab}}$ & $\mathrm{ab}$ & \\
$F$ & 156.58 & 90.94 & 73.02 \\
$P$-value & $<0.001$ & $<0.001$ & $<0.001$ \\
\hline Values & & & \\
\end{tabular}

Values are expressed as med compared with the sham operation group; ${ }^{b} p<0.05$, compared with the model group

\section{Protein expression levels of TRPV1 channel in rat spinal cord tissue}

As shown in Figures 2 and 3 and in Table 4, relative to sham operation group, TRPV1
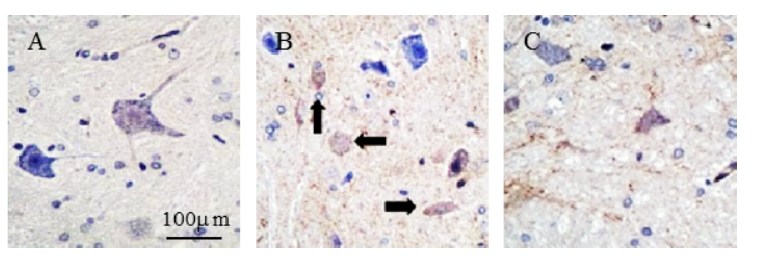

Figure 2: Expression levels of TRPV1 channel protein in rat spinal cord tissue. A: sham operation group, B: model group, C: pregabalin group

channel protein in the spinal cord of model rats was markedly up-regulated. However, the corresponding TRPV1 channel protein level in spinal cord of pregabalin-exposed rats was markedly decreased, relative to $\mathrm{PN}$ model group $(p<0.05)$.

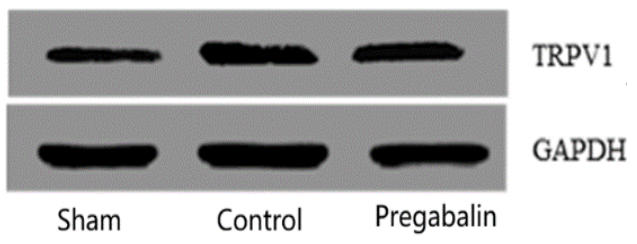

Figure 3: Expression level of TRPV1 channel protein in rat spinal cord tissue. ${ }^{a},{ }^{b} P<0.05$, vs sham operation rats $\left({ }^{a}\right)$; vs model rats $\left({ }^{b}\right)$

Table 4: Expression levels of TRPV1 channel protein in rat spinal cord tissue (mean $\pm \mathrm{SD}$ )

\begin{tabular}{lc}
\hline Group & TRPV1 \\
\hline Sham & $0.13 \pm 0.02$ \\
Model & $0.19 \pm 0.03^{\mathrm{a}}$ \\
Pregabalin & $0.16 \pm 0.02^{\mathrm{ab}}$ \\
$F$ & 19.06 \\
$P$-value & $<0.001$ \\
\hline${ }^{\mathrm{a}, \mathrm{b}} P<0.05$, vs sham $\left({ }^{\mathrm{a}}\right) ; \mathrm{vs}$ model $\left({ }^{\mathrm{b}}\right)$
\end{tabular}

\section{DISCUSSION}

Postherpetic neuralgia is a neuropathic pain caused by herpes zoster virus as a result of sensory nervous system injury, and it manifests mainly as persistent, paroxysmal, spontaneous knife pain or hyperalgesia. The pathogenesis of this disease is still poorly understood. However, it is believed that it may be closely related to age, regulation of expressions of related genes, and changes in immune function [6]. Age is the most important risk factor for postherpetic neuralgia. Statistics have shown that more than $13 \%$ of herpes zoster patients aged over 55 years develop postherpetic neuralgia, the incidence of which increases with age, with negative impact on the physical and mental health of patients [7].

At present, the clinical treatment of postherpetic neuralgia uses mainly non-steroidal antiinflammatory drugs and opioids which are aimed 
at pain relief and improvement of quality of life, but long-term use of these drugs results in high degree of toxic and side effects [8]. Therefore, it will be of great significance to identify new drugs with lower adverse reactions and higher efficacy. Being an anti-epileptic drug, pregabalin selectively binds to $\alpha 2-\delta$ subunits of calcium ion channels, reduces the influx of calcium ions and inhibits the release of excitatory neurotransmitters, thereby producing analgesic effects. Moreover, its effect is faster and its safety is higher than those of other drugs [9]. Bihong et al found that after pregabalin treatment, patients with postherpetic neuralgia had significantly reduced pain scores and improved sleep quality [10]. In this study, the mechanism involved in pregabalin-induced mitigation of postherpetic nerve pain was determined and analyzed.

While pain is an unpleasant feeling or emotional experience related to actual or potential tissue damage, and an important pathophysiological reflex, neuropathologic pain lasts for a long time and seriously affects the life of the patient [11]. In this study, the TMPTs of each group of rats were determined. The results showed that pregabalin significantly relieved abnormal mechanical pain and thermal pain in rats with postherpetic nerve pain. This is in agreement with findings in studies which reported that pregabalin inhibited the excitability of cell membranes of nociceptive sensory neurons of the central nervous system, suppressed the transmission between synapses, and regulated the plasticity of associated neurons [12].

The spinal cord and brain play important roles in the pathogenesis of neuropathic pain, being vital control centers of the body [13]. Studies have shown that the activation of astrocytes promotes the release of TNF- $\alpha$ and other inflammatory factors, thereby aggravating the occurrence of neuropathic pain [14]. This investigation has demonstrated that pregabalin inhibited the activation of astrocytes in spinal dorsal horn, prefrontal lobe and hippocampus, and suppressed inflammatory response in spinal dorsal horn.

The transient receptor potential vanilloid type1 (TRPV1) is an important nociceptor molecule found in unmyelinated class $C$ fibers and in some Aঠ fibers in the dorsal root ganglion; it is closely related to a variety of physiological and pathological processes [15]. A variety of inflammatory substances or mediators sensitize TRPV1, leading to release of substance $P$, thereby producing pain sensation. The results of this study showed that TRPV1 level in the spinal cord of model rats was markedly increased [16]. This may be due to formation of local inflammation in the rat model of postherpetic nerve pain which resulted in an acidic environment which activated TRPV1 and enhanced pain generation, leading to occurrence of hyperalgesia [17-19]. However, pregabalin significantly down-regulated the expression of TRPV1.

\section{CONCLUSION}

This study has demonstrated that pregabalin significantly alleviates postherpetic nerve pain via a mechanism which may be related to inflammatory responses in spinal dorsal horn tissue, and downregulation of the expression of TRPV1 channel protein. This finding may be useful in developing new drugs for alleviating postherpetic neuralgia.

\section{DECLARATIONS}

\section{Acknowledgement}

This research was supported by Clinical Innovation Guiding Project of Science and Technology Department of Hunan Province (no. 2018SK51511).

\section{Conflict of interest}

No conflict of interest is associated with this work.

\section{Authors' contribution}

We declare that this work was performed by the authors named in this article and all liabilities pertaining to claims relating to the content of this article will be borne by the authors. Cong Zou designed the study, supervised the data collection, and analyzed the data. Zhenping Xiao interpreted the data and prepared the manuscript for publication. Mengjun Liao, Yunwu He, Yonglin Li, Wuzhou Yang and Liping Jiang supervised the data collection, analyzed the data and reviewed the draft of the manuscript.

\section{Open Access}

This is an Open Access article that uses a funding model which does not charge readers or their institutions for access and distributed under the terms of the Creative Commons Attribution License (http://creativecommons.org/licenses/by/ 4.0) and the Budapest Open Access Initiative (http://www.budapestopenaccessinitiative.org/rea 
d), which permit unrestricted use, distribution, and reproduction in any medium, provided the original work is properly credited.

\section{REFERENCES}

1. Foster O, Askaria A, Lanham J, Perry D. Algoneurodystrophy following herpes zoster. Postgrad Med J 1989; 65(765): 478-480.

2. Dai $H$, Jiang $C, W u G$, Huang $R$, Jin $X$, Zhang Z, Wang $L$, Li Y. A combined DTI and resting state functional MRI study in patients with postherpetic neuralgia. Jpn J Radiol 2020; 38(5): 440-450.

3. Kang HY, Lee CH, Choi SS, Lee MK, Park JS, Oh JS. Comparison of ropivacaine with ropivacaine and fentanyl in continuous epidural analgesia for postherpetic neuralgia: A STROBE-compliant retrospective study. Medicine (Baltimore) 2020; 99(22): e20298.

4. Ryan NM, Vertigan AE, Birring SS. An update and systematic review on drug therapies for the treatment of refractory chronic cough. Expert Opin Pharmacother 2018; 19(7): 687-711.

5. World Health Organization. Principles of laboratory animal care. WHO Chron 1985; 39: 51-56.

6. Lee CH, Choi SS, Lee MK, Lee YJ, Park JS. Efficacy of continuous epidural infusion with epidural electric stimulation compared to that of conventional continuous epidural infusion for acute herpes zoster management: a retrospective study. BMC Anesthesiol 2020; 20(1): 1-26.

7. van Oorschot DAM, Hunjan $M$, Bracke $B$, Lorenc $S$, Curran D, Starkie-Camejo H. Public health impact model estimating the impact of introducing an adjuvanted recombinant zoster vaccine into the UK universal mass vaccination programme. BMJ Open 2019; 9(5): e025553.

8. Lee SH, Ryu KH, Kim PO, Lee HW, Cho EA, Ahn JH, Youn I, Yang KS. Efficacy of extracorporeal shockwave therapy in the treatment of postherpetic neuralgia: $A$ pilot study. Medicine (Baltimore) 2020; 99(12): e19516.

9. Vallejo $R$, Kramer J, Benyamin R. Neuromodulation of the cervical spinal cord in the treatment of chronic intractable neck and upper extremity pain: a case series and review of the literature. Pain Physician 2007; 10(2): 305-311.
10. Hong B, Sun J, Zheng H, Le Q, Wang C, Bai K, He J, He $H$, Dong Y. Effect of Tetrodotoxin Pellets in a Rat Model of Postherpetic Neuralgia. Mar Drugs 2018; 16(6): 195.

11. Song $D, H e A, X u R$, Xiu X, Wei Y. Efficacy of Pain Relief in Different Postherpetic Neuralgia Therapies: A Network Meta-Analysis. Pain Physician 2018; 21(1): 1932.

12. Chen JY, Lin $Y T$, Wang $L K$, Hung $K C$, Lan $K M$, Ho $C H$, Chang CY. Hypovitaminosis Din Postherpetic NeuralgiaHigh Prevalence and Inverse Association with Pain: A Retrospective Study. Nutrients 2019; 11(11): 27672787.

13. Vallejo R, Kramer J, Benyamin R. Neuromodulation of the cervical spinal cord in the treatment of chronic intractable neck and upper extremity pain: a case series and review of the literature. Pain Physician 2007; 10(2): 305-311.

14. Liu $Y$, Wang $M$, Xiong $M M$, Zhang $X G$, Fang $M$. Intravenous Administration of Vitamin $C$ in the Treatment of Herpes Zoster-Associated Pain: Two Case Reports and Literature Review. Pain Res Manag 2020; 2020: 8857287.

15. Xing X, Bai Y, Sun K, Chen Q, Huang H, Qiu W, Yan M. Identification of Candidate Genes Associated with Postherpetic Neuralgia Susceptibility. Pain Physician 2020; 23(3): 281-288.

16. Zhang $C$, Ye $L$, Zhang $Q$, Wu F, Wang $L$. The role of TRPV1 channels in atherosclerosis. Channels (Austin) 2020; 14(1): 141-150.

17. Tian YH, Ma SX, Lee KW, Wee S, Koob GF, Lee SY, Jang CG. Blockade of TRPV1 Inhibits Methamphetamine-induced Rewarding Effects. Sci Rep 2018; 8(1): 879-882.

18. Zhuang $X$, Huang $L, G u Y$, Wang $L$, Zhang $R$, Zhang $M$, Li F, Shi $Y$, Mo $Y$, Dai $Q$, et al. The anterior cingulate cortex projection to the dorsomedial striatum modulates hyperalgesia in a chronic constriction injury mouse model. Arch Med Sci 2019; 17(5): 1388-1399.

19. Tan W, Qian DC, Zheng MM, Lu X, Han Y, Qi DY. Effects of different doses of magnesium sulfate on pneumoperitoneum-related hemodynamic changes in patients undergoing gastrointestinal laparoscopy: a randomized, double-blind, controlled trial. BMC Anesthesiol 2019; 19(1): 230-237. 